\title{
Features of the experimental determination of the elastic characteristics of epoxy resin with the addition of silicon dioxide nanoparticles
}

\author{
Artem Filippov* \\ Khristianovich Institute of Theoretical and Applied Mechanics SB RAS, 630090 Novosibirsk, Russia
}

\begin{abstract}
Current work describes experimental determination Young modulus of polymer composition based on epoxy resin filled two types of silicon dioxide nanoparticles with different average diameter. It is shown, that each type of powder differently increases the Young's modulus of the epoxy resin for constant concentration. For Tarkosil powders, the increase in Young's modulus for filled epoxy was from 7 to $25 \%$ with a decrease in the average particle diameter from 48 to $18 \mathrm{~nm}$. The change in the Young's modulus of the polymer is significantly less with the addition of Aerosil powders. Young's modulus increased from 0 to $15 \%$ with diameters from 12 to $8 \mathrm{~nm}$.
\end{abstract}

\section{Introduction}

The choice of mechanical tests for a particular material is determined primarily by the magnitude and effect of the load to which it will be overcome during exploitation [1]. In other side, to realize the stress state in which the field of stresses and strains can be calculated analytically, standardized shapes and sizes of test specimens are required depending for each type of material and the loading method. To compare the mechanical properties of materials, standardized tests have been developed. Requirements for testing machines, test specimens, test methods are determined by state and industry standards. In most standardized tests, one elastic characteristic of the material is determined in one experiment. Additional tests are performed to determine the remaining or local characteristics [2]. Features of sample preparation, testing, and processing of experimental data can lead to large errors in the determination of elastic modules. As a result of mechanical testing, the dependence of the applied load on the change in the shape and size of the sample, usually expressed in the stress-strain coordinates, is obtained. The processing of stress-strain curves can be carried out in various ways, and from the choice of methods for determining certain parameters, the determined characteristics also change. The calculation method is determined by standards, therefore, for different materials, you should choose different algorithms for determining certain graph values. Incorrect selection of the algorithm can lead to significant deviations from the reference values and systematic errors. So, the processing of the stress-straincurve to determine the Young's modulus E can

\footnotetext{
* Corresponding author: filippov@itam.nsc.ru
} 
be carried out in various ways. Generally speaking, in the linear theory of elasticity, Young's modulus is defined as the angle of inclination of the stress-strain curve on a specific section and is displayed as an oblique straight line. However, the obtained graphs in reality can only be approximated to some extent by the straight lines, due to the peculiarities of preload, the influence of captures, measured equipment, etc. Therefore, the plots of the stress-strain graphs on which it is necessary to determine the Young's modulus in tension can be processed using various algorithms.

\section{Materials}

The object of research is the thermosetting resin DER-330 (Dow chemical, USA), filled with silicon dioxide nanopowders of different dispersion from two manufacturers: 3 types of Aerosil (Evonik, Germany) [3], 3 types of Tarkosil (INP-ITAM, Russia) [4].

Table 1. Characteristics of the components of the thermosetting compound.

\begin{tabular}{|c|c|c|c|c|}
\hline Component & Colour & $\begin{array}{c}\text { Dynamic } \\
\text { viscosity at 25 } \\
\mathbf{C}, \mathbf{P a} \bullet\end{array}$ & $\begin{array}{c}\text { Density at } \\
\mathbf{2 5}^{\circ} \mathbf{C}\end{array}$ & $\begin{array}{c}\text { Mass fraction of epoxy } \\
\text { groups/anhydride, } \%\end{array}$ \\
\hline D.E.R.-330 & transparent & $7-10$ & 1.16 & $23.2-24.4$ \\
\hline IMTHPA & $\begin{array}{c}\text { Light } \\
\text { yellow }\end{array}$ & 0.1 & 1.21 & 40.5 \\
\hline
\end{tabular}

A total of 3 types of compositions were made: the concentration was 2 wt. \% for 6 types of powders. The powder was mixed mechanically with the hardener. Then the mixture was mixed with an ultrasonic homogenizer HD3200 (Bandelin, Germany). A titanium flat probe with a diameter of $13 \mathrm{~mm}$ was immersed in a solution of a hardener with a powder and worked on the mixture for 3 minutes, heating to $40-50^{\circ} \mathrm{C}$ and causing cavitation effects. As a result, the hardener changed color from a clear light yellow to an opaque white. Then epoxy resin was added to the mixture and mechanically stirred for 1 minute. The ratio of powder, hardener and resin was 2:80:100, respectively. The resulting mixture was poured into aluminum flat forms and placed in an FD53 drying oven (Binder, Germany) for further curing [5, 6]. Curing was carried out in a stepped mode of $100^{\circ} \mathrm{C} / 2 \mathrm{~h}+160^{\circ} \mathrm{C} / 10 \mathrm{~h}+110^{\circ}$ $\mathrm{C} / 2 \mathrm{~h}$ with an accuracy of $2^{\circ}$.

Table 2. Characteristics of the used powders of silicon dioxide.

\begin{tabular}{|c|c|c|c|}
\hline Powder name & $\begin{array}{c}\text { Specific } \\
\text { surface } \\
\text { area, } \mathbf{~ m}^{2} / \mathbf{g}\end{array}$ & Bulk density, $\mathbf{g} / \mathbf{m}^{\mathbf{3}}$ & $\begin{array}{c}\text { The theoretical average particle } \\
\text { diameter of the powder, } \mathbf{~ m m}\end{array}$ \\
\hline Aerosil A-200 & 199 & $50-60$ & 6.25 \\
\hline Aerosil A-300 & 280 & $50-60$ & 4.5 \\
\hline Aerosil A-380 & 242 & $50-60$ & 5.2 \\
\hline Tarkosil T-05 & 50 & $70-80$ & 20.8 \\
\hline Tarkosil T-15 & 96 & $70-80$ & 13.9 \\
\hline Tarkosil T-20 & 134 & $60-70$ & 9.3 \\
\hline
\end{tabular}

\section{Methods of mechanical testing}

In the present work, for the experimental study of the mechanical properties of the materials under study, we used a number of standard test facilities, which allows us to determine a wide range of mechanical characteristics of various materials. Used in experiments test facilities are standard in their class of machines with a force of up to $10 \mathrm{kN}$. This class of 
facilities is characterized by high accuracy in measuring strain and effort, as well as ample opportunities for the modernization and installation of additional devices. The machines consist of a rigid frame, a strain gauge, an electric motor, two rigid clamps and a computer for fine-tuning the load settings. Testing facilities allow you to process data in real time with a frequency of up to $500 \mathrm{~Hz}$. Monitoring and control are focused on determining the event during the test (for example, a change in speed when the yield strength or deformation limit is reached), which made it possible to determine the elastic modulus during the test automatically. The lower support is rigidly fixed to the frame, and the upper, mounted on the cross-beam, is moved using a stepper motor. Between the cross-beam and the upper support there is an S-shaped force transducer that converts the deformations into the calculated loads.

Table 3. Test equipment.

\begin{tabular}{|c|c|c|}
\hline Technical Data/Installation Name: & Zwick/Roell Z 005 & Zwick/Roell Z 100 \\
\hline Nominal force & $\mathrm{F}_{\mathrm{n}}=5 \mathrm{kN}$ & $\mathrm{F}_{\mathrm{n}}=100 \mathrm{kN}$ \\
\hline Maximal force & $120 \% \mathrm{~F}_{\mathrm{n}}$ & $120 \% \mathrm{~F}_{\mathrm{n}}$ \\
\hline Limit of loading & $150 \% \mathrm{~F}_{\mathrm{n}}$ & $150 \% \mathrm{~F}_{\mathrm{n}}$ \\
\hline Loading speed & $\begin{array}{c}\text { From } 0,0005 \text { to } 1500 \\
\mathrm{~mm} / \mathrm{min}\end{array}$ & $\begin{array}{c}\text { From } 0,0005 \text { to } 300 \\
\mathrm{~mm} / \mathrm{min}\end{array}$ \\
\hline $\begin{array}{c}\text { Resolution of the stepper motor } \\
\text { movement system }\end{array}$ & $\pm 2 \mu \mathrm{m}$ & $\pm 2 \mu \mathrm{m}$ \\
\hline $\begin{array}{c}\text { Resolution of the contact strain gauge } \\
\text { - extensometer }\end{array}$ & - & $0,08 \mu \mathrm{m}$ \\
\hline
\end{tabular}

Evaluation of the influence of the size of the sample to determine Young's modulus without using a contact strain gauge (extensometer) was carried out on castings without nanopowder. For this, rectangular types of epoxy resin specimens of two types: 4x8 and $4 \times 6 \mathrm{~mm}^{2}$ were subjected to uniaxial tension on a Z005 (Zwick/Roell, Germany) installation under the same loading conditions: $50 \mathrm{~N}$ preload, traverse movement control at a speed of 1 $\mathrm{mm} / \mathrm{min}$ at room temperature. The determination of the elastic modulus was carried out according to the stress-strain curve in the area of $1-2 \%$ strain. The working length ranged from 15 to $120 \mathrm{~mm}$. Figure 1 shows that the Young's modulus of elasticity calculated in this way substantially depends on the length of the sample. The movement of the sample itself is combined with the movements within the loaded system of fasteners, grips and traverse, as well as the force detection sensor, introducing a significant systematic error in the determination of Young's modulus. With an increase in the length of the sample, its displacement under load increases, which becomes significantly larger than the elements of the loaded system at a working distance of $100 \mathrm{~mm}$. Both types of samples behave in the same way, with a sample of a smaller cross section with a smaller area reaching the constant modulus values.

The influence of the loading rate was estimated on specimens of pure epoxy resin in the range from 0.1 to $10 \mathrm{~mm} / \mathrm{min}$. For this, rectangular cross-sectional specimens of $50 \times 10$ $\mathrm{mm}^{2}$ were tested for uniaxial compression at different speeds of cross-beam movement. In the entire considered range of loading rates, the magnitude of the module was within the error.

The influence of the average particle size of the filler on the Young's modulus of elasticity under uniaxial tension was evaluated on flat specimens of rectangular section $160 \times 3 \times 7 \mathrm{~mm}^{3}$. The mass concentration of the filler for all compositions was $2 \%$ by mass. The length of the working part was $100 \mathrm{~mm}$. Uniaxial tensile testing of the specimens in wedge-shaped grips was carried out in a Z 005 (Zwick/Roell, Germany) testing machine at a speed of $400 \mathrm{~N} / \mathrm{min}$ at room temperature $25^{\circ} \mathrm{C}$. To reduce the nonlinear effects arising from the slight displacement of the clamps, the specimens were preloaded at $50 \mathrm{~N}$. The 
loading limit was $35 \mathrm{MPa}$. The elastic modulus was calculated on the stress-strain curve by the secant method in the deformation section of $1-2 \%$. For each type of powder 3 specimens were tested.
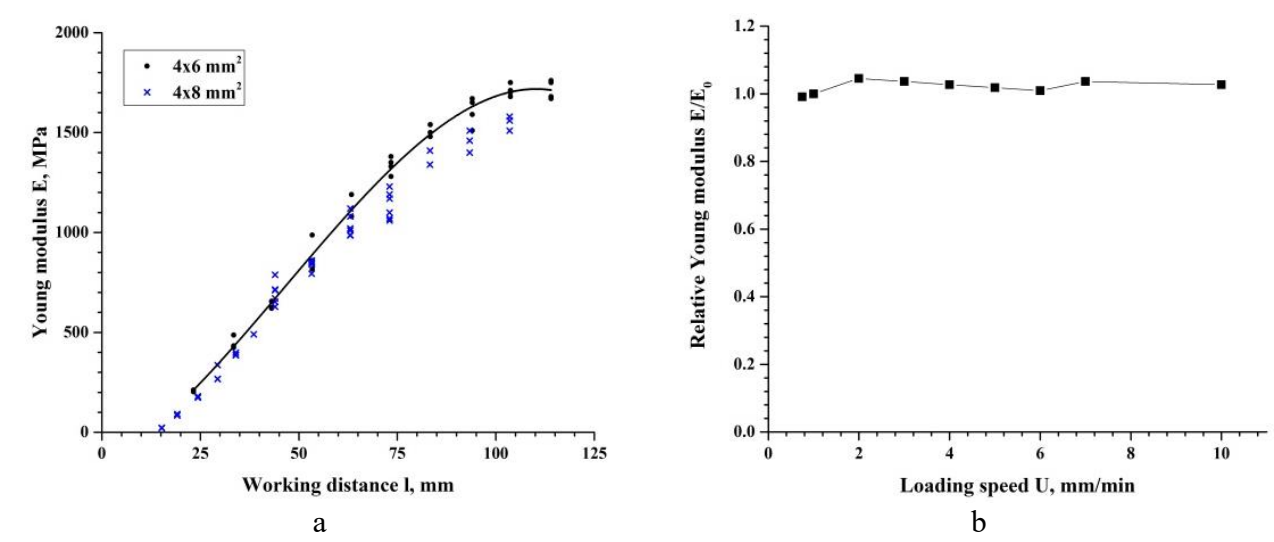

Fig. 1. Influence of test parameters on Young's modulus of uniaxial tension: a - dependence on the working length of the sample; $b$ - load rate dependence.

Uniaxial compression tests were carried out on the same resin compositions with nanopowder in a Z 010 (Zwick/Roell, Germany) flat support installation. For uniaxial compression tests, cylindrical specimens with a diameter of $6 \mathrm{~mm}$ and a height of $25 \mathrm{~mm}$ were used. The preload was $50 \mathrm{~N}$, the test speed $2 \mathrm{~mm} / \mathrm{min}$ at room temperature $25^{\circ} \mathrm{C}$. The determination of the modulus of elasticity was carried out by the secant method on the stress-strain diagram, according to the formulas given above, in the stress range from $\sigma_{1}=10 \mathrm{MPa}$ to $\sigma_{2}=20 \mathrm{MPa}$. Strains $\varepsilon_{1}$ and $\varepsilon_{2}$ at stresses $\sigma_{1}$ and $\sigma_{2}$ determined by diagrams. Young's modulus was calculated by the formula:

$$
E=\frac{\sigma_{2}-\sigma_{1}}{\varepsilon_{1}-\varepsilon_{2}}
$$

As a result, it was found that each type of powder differently increases the Young's modulus of the epoxy resin for constant concentration (Fig. 2).

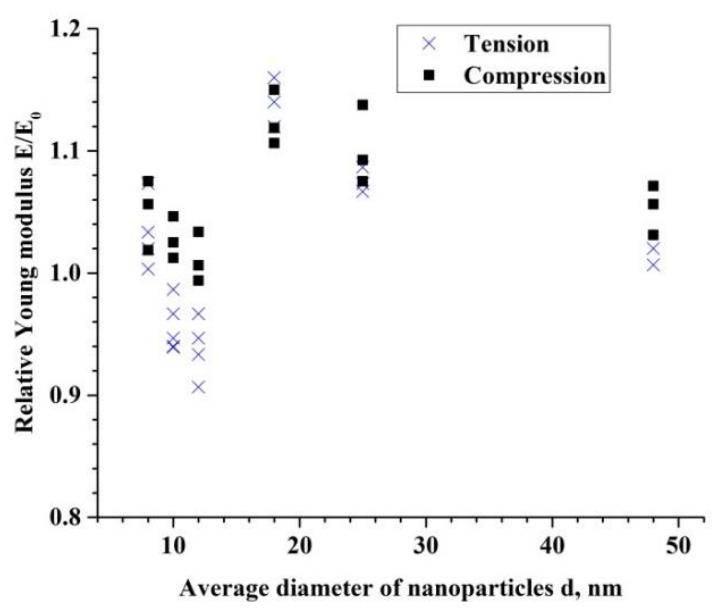

Fig. 2. The dependence of the Young's modulus on the average particle size of the filler under uniaxial tension and compression. 
For Tarkosil powders, the increase in Young's modulus for filled epoxy was from 7 to $25 \%$ with a decrease in the average particle diameter from 48 to $18 \mathrm{~nm}$. The change in the Young's modulus of the polymer is significantly less with the addition of Aerosil powders. Young's modulus increased from 0 to $15 \%$ with diameters from 12 to $8 \mathrm{~nm}$. The error of the experimental results is about $5 \%$. Changes in the elastic moduli of polymer compositions under tension and compression coincide.

\section{Conclusion}

As a result of mechanical tests, the size of the samples made of epoxy resin was determined at which a uniaxial tensile state is realized. In the considered range of loading rates, material loading can be considered independent of the loading rate. Experimental dependences of the elastic characteristics of a heterogeneous material based on an epoxy resin filled with nanosized particles of silicon dioxide are obtained. Depending on the type of powder used, the increase in elastic characteristics is different. A decrease in the particle diameter of the filler leads to an increase in the elastic modulus at a constant concentration for each filler (Aerosil and Tarkosil).

The research was carried out within the framework of the Program of Fundamental Scientific Research of the state academies of sciences in 2013-2020 (project No. AAAA-A17-117030610134-9) using the equipment of the Joint Access Center «Mechanics» of ITAM SB RAS.

\section{References}

1. M. F. Ashby, D. R. H. Jones, Engineering materials: An Introduction to Properties, Applications and Design (Elsevier, Butterworth-Heinemann, 2005)

2. S. V. Smirnov et. al., Mech. of Composite Mat. 55(3) 483-500 (2019)

3. Evonik Industries AG; Silica Business Line AEROSIL - Fumed Silica Technical Overview

4. S. P. Bardakhanov et al., Mat. Sci. and Eng.B 132, 204-208 (2006).

5. T. A. Brusentseva et al., Mech. of Composite Mat. 51(4) 531-538 (2015)

6. T. A. Vaganova et. al., J. Polym. Res. 21:588 (2014) 